\title{
openheart Mental symptoms in patients with cardiac symptoms and normal coronary arteries
}

\author{
Marian Christoph, ${ }^{1}$ Antje Christoph, ${ }^{2}$ Stephanie Dannemann, ${ }^{3}$ David Poitz, ${ }^{1}$ \\ Christian Pfluecke, ${ }^{1}$ Ruth H Strasser, ${ }^{1}$ Carsten Wunderlich, ${ }^{1}$ Volker Koellner, ${ }^{4}$ \\ Karim Ibrahim ${ }^{1}$
}

To cite: Christoph M, Christoph A, Dannemann S, et al. Mental symptoms in patients with cardiac symptoms and normal coronary arteries. Open Heart 2014:1:e000093.

doi:10.1136/openhrt-2014000093

\section{- Additional material is available. To view please visit the journal (http://dx.doi.org/ 10.1136/openhrt-2014- 000093).}

\section{$\mathrm{MC}, \mathrm{AC}, \mathrm{VK}$ and $\mathrm{KI}$} contributed equally.

Received 26 February 2014 Revised 19 July 2014 Accepted 4 August 2014

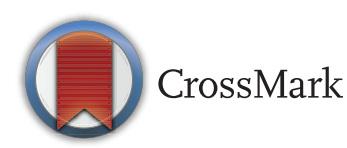

\footnotetext{
${ }^{1}$ University of Dresden, Heart Centre University Hospital, Dresden, Germany

2Department of Medicine III, University Hospital Dresden, Dresden, Germany

${ }^{3}$ Department of

Psychosomatics and Psychotherapy, University Hospital Dresden, Dresden, Germany

${ }^{4}$ Department of

Psychosomatic Medicine Bliestal Clinic, Homburg/Saar, Germany
}

Correspondence to Dr Marian Christoph; Marian.Christoph@mailbox. tu-dresden.de

\begin{abstract}
Objectives: Patients with chest pain and normal coronary arteries often suffer from physical and psychological symptoms. Therefore, this study aimed to examine the incidence of mental symptoms in patients with angiographic exclusion of a coronary heart disease.

Design: In 253 patients with angiographic exclusion of a coronary heart disease the type and intensity of their symptoms were evaluated before and after coronary angiography. In addition, the incidence of psychopathological symptoms was quantified by standardised questionnaires such as general anxiety and depression (HADS), heart-focused anxiety (CAQ), hypochondria (Whiteley Index) and somatoform disorder (SOMS) and quality of life (SF-12). Finally, the incidence of psychological symptoms in these patients was compared to the incidence in the normal population.
\end{abstract}

Results: Despite the absence of a coronary artery disease, $70 \%$ of patients continue to suffer from cardiac symptoms. The incidence of general anxiety was increased by $37 \%$ in women and by $22 \%$ in men in comparison to the normal population. Heart-focused anxiety was raised by $27 \%$. Somatoform disorder appeared $120 \%$ more often in patients after cardiac catheterisation in comparison to the normal population. In addition, the incidence of hypochondria was elevated by $68 \%$ in patients after coronary angiography compared to normal population. This increased appearance of psychological symptoms was reflected in a significantly lower quality of life (SF-12) in patients with inconspicuous coronary angiography.

Conclusions: Patients with cardiac symptoms and normal coronary arteries more often suffer from mental symptoms in comparison to the healthy population.

\section{INTRODUCTION}

The heart is popularly known as the seat of the soul. Physical as well as emotional stress can affect our heartbeat. More than 2000 years ago the Roman author of encyclopaedic writings, Aulus Cornelius Celsus, noted that 'anxiety and anger as well as other states

\section{KEY MESSAGES}

What is already known about this subject?

- About $20 \%$ of patients with chest pain have normal coronary angiograms. Psychopathological disorders are important differential diagnoses in these chest pain patients. As this diagnosis is often not recognised, the healthcare system is heavily burdened.

What does this study add?

- This study provides diagnostic tools for detection of psychosomatic symptoms in chest pain patients without a somatic cause.

How might this impact on clinical practice?

- These diagnostic tools may prevent repeated utilisation of the healthcare system and this could help to reduce costs in these patients due to initiation of an early psychosomatic therapy.

of mind often accelerate the pulse rate' and, therefore, they could have influence on the activity of the heart. ${ }^{1}$ Furthermore, psychological disorders like depression and posttraumatic stress disorder may increase the risk of cardiovascular mortality. ${ }^{2}{ }^{3}$ With this high emotional importance, which is ascribed to the heart, it is obvious that psychological disorders like depression, anxiety and somatoform disorders or hypochondria often manifest themselves in cardiac symptoms, although the affected patients do not have any organic heart disease. ${ }^{4}$ Even in young adults chest pain is strongly associated with psychiatric disorders. ${ }^{5}$ Recent studies have shown that patients with non-cardiac chest pain, compared to patients with coronary heart disease, suffer similar or more from psychopathological disorders. ${ }^{6}$

This correlation between heart function and the emotional state aroused interest among cardiologists and psychiatrists equally. ${ }^{7}$ 
Despite this high importance, in patients with noncardiac chest pain, mental disorders are often diagnosed too late, because cardiologists without psychosomatic experience lack uncomplicated diagnostic tools to detect them accurately. ${ }^{8}$ Owing to this diagnostic gap and the unclear incidence of psychopathological disorders in patients with non-cardiac chest pain in everyday routine, an expansion of unnecessary somatic diagnostic procedures and therapy is preferred by general practitioners, which is associated with significant morbidity, reduced quality of life for affected patients and excessive healthcare utilisation. $^{9-11}$

Therefore, we conducted the current study to test the hypothesis that patients with cardiac symptoms and normal coronary arteries have an increased incidence of mental symptoms. For the diagnosis of mental symptoms, different well-validated questionnaires were developed in the past, which assess the cardiac symptoms and sensations as well as related behaviour. These questionnaires were used to examine patients with cardiac symptoms but without organic heart disease. The resulting incidences of mental symptoms were finally compared with the incidences in the normal population.

\section{METHODS}

\section{Overview}

The study was designed to examine, within 1 year, consecutive patients of the Department of Cardiology, Faculty of Medicine, Dresden who underwent a coronary angiography that excluded a relevant coronary artery disease. Written informed consent was obtained from each patient prior to enrolment in the prospective registry. All data were collected, managed and analysed at the Heart Centre, University of Dresden. We conducted one assessment after cardiac catheterisation using validated questionnaires (figure 1). To compare the collected data of the cardiac symptomatic patients with the healthy population, we used as comparison samples participants without history of any cardiac disease. For this purpose representative samples for the adult population

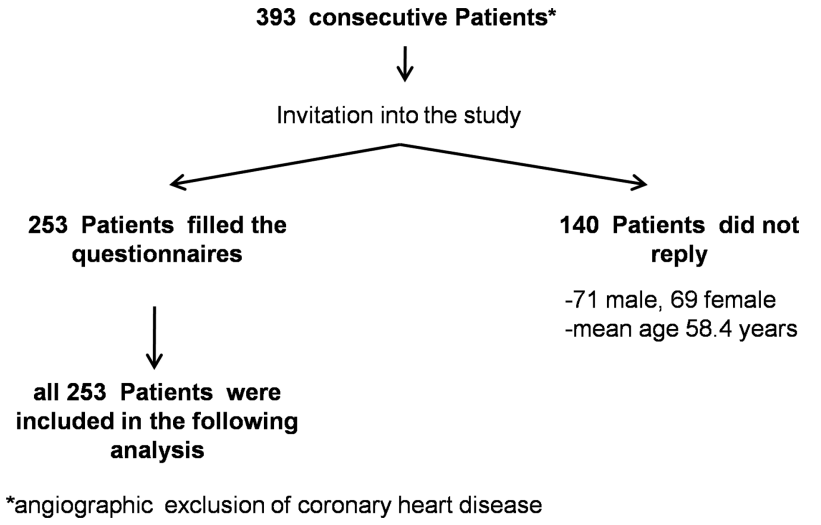

Figure 1 Flow chart of study design and in/excluded patients. of Germany were selected. These samples were selected from previous published articles. In these studies representative samples of the general population of Germany were selected.

\section{Participants}

The study was conducted in the Heart Centre Dresden. Eligibility criteria were as follows:

- Presence of at least one of the following cardiac symptoms: chest pain, dyspnoea, palpitations;

- Exclusion of a relevant coronary artery disease in coronary angiography;

- Preserved left and right ventricular systolic function;

- Exclusion of valvular heart disease in echocardiography;

- Age of 18 years or older;

- Native language German.

Reasons for exclusion were relevant coronary artery disease, haemodynamic relevant valvular heart disease, decreased ventricular ejection fraction and documented cardiac arrhythmia.

\section{Measures}

All questionnaires were sent by mail in June of the following year to all identified patients who had an angiographic exclusion of a coronary heart disease within the same previous year (from January to December). Accordingly, a period of 6-18 months was set aside between the coronary angiography and the survey.

The type, intensity and duration of the cardiac symptoms were measured with a not standardised questionnaire. This questionnaire contains 11 items with dichotomous and five-point Likert-type scale answer categories (see the German version in the online supplement material).

Cardiac Anxiety Questionnaire (CAQ) is a 17-item selfreport inventory scored on a five-point Likert-type scale, anchored from 0 (never) to 4 (always). ${ }^{12}$ The CAQ includes three subscales:

A. Fear (8 items);

B. Avoidance (5 items);

C. Attention (5 items).

Higher scores on this Questionnaire indicate greater anxiety. The CAQ has an adequate convergent validity with an Anxiety Sensitivity Index. ${ }^{13}$ Additionally, the CAQ has been found to be a cognitive behaviour therapy outcome measure. ${ }^{14}$ As comparison, sample patients without history of any cardiac disease were used. The comparison sample was matched with the sample of cardiac patients with regard to the age $(n=72$; age: mean $=65.5$ years $).{ }^{15}$

Hospital Anxiety and Depression Scale (HADS) is a 14-item self-report measure containing two subscales of anxiety (7 items) and depression (7 items). ${ }^{16}$ We used the German version of HADS, which has been found to have good psychometric properties. ${ }^{17}$ For comparison of the cardiac patients the normal values of the Hospital Anxiety and Depression Scale were used. The normal 
values were matched with regard to the age $(n=666$; age $>60$ years). ${ }^{18}$

The 'Screening for Somatoform Disorders' (SOMS) is based on the somatisation index (cut-off: 4 for male, 6 for female) and makes it possible in the form of self-rating to record 53 physical symptoms from the Diagnostic and Statistical Manual-IV (DSM-IV) that were present during the past 2 years (SOMS-2) and that were not attributable to an organic cause. ${ }^{19}$ The somatisation severity index results in the mean of all item answers. Reliability and validity of that index is satisfactory. ${ }^{20}$ As comparison sample data of German non-clinical age-matched participans were used $(\mathrm{n}=101) .{ }^{19} 21$

The Whiteley Index (WI) is a 14-item self-report questionnaire to measure hypochondriacal tendencies. ${ }^{22}$ The answer categories are dichotomous, yes or no. The instrument consists of a total score and three subscales labelled Disease Phobia (6 items), Somatic Symptoms (3 items) and Disease Conviction (4 items) ${ }^{23}$ From a total value greater than 8 (positively answered questions) $78 \%$ of people with hypochondria are detected. ${ }^{17} 2224$ For comparison of the cardiac patients, the normal values of the Whiteley Index were used. The normal values were based on a study of healthy participants $(\mathrm{n}=2050){ }^{21}$

12-Item Short-Form Health Survey (SF-12) is used to assess quality of life in relation to physical and mental health. ${ }^{25}$ The SF-12 survey consists of two scores: a physical impairment score and a psychological impairment score. A higher score indicate a better health status. Is has been shown that this questionnaire has good psychometric properties. ${ }^{26}$ As comparison data a non-clinical German normative sample of the same age cohort (416 men and women) was used. ${ }^{27}$

\section{Statistical analyses}

$t$ Test for single means were calculated to examine differences between the study sample and the comparison samples. Level of significance was set at $\mathrm{p}<0.05$. Results are expressed as mean \pm SD. Spearman's rank correlation coefficient was used to determine relations between persistence of cardiac symptoms and mental symptoms as well as between mental symptoms and the quality of life. Low correlation between the variables was set at Spearman correlation coefficient $(\mathrm{r}(\mathrm{s}))$ 0.2-0.5. Moderate correlation was defined at $\mathrm{r}(\mathrm{s})$ 0.5-0.7.

\section{RESULTS}

\section{Patients and demographics}

All consecutive patients with an angiographic exclusion of a coronary heart disease of one calendar year from January to December were invited into the study.

In total 393 patients were invited into the study. Of these patients, 253 participants filled the questionnaires completely (64.4\%) 97 men $(38.3 \%)$ and 156 women $(61.7 \%)$. Participants' mean age was 64.5 years.

\begin{tabular}{|c|c|c|}
\hline & Male & Female \\
\hline Total patient number, n (\%) & 97 (38.3) & $156(61.7)$ \\
\hline Age mean, years (SD) & $60.8(10.63)$ & $66.7(8.8)$ \\
\hline Hypertension, n (\%) & $37(38.1)$ & $80(51.3)$ \\
\hline Diabetes, n (\%) & $12(12.4)$ & $14(9)$ \\
\hline Smoker, n (\%) & $11(11.3)$ & $4(2.6)$ \\
\hline $\begin{array}{l}\text { Left ventricular ejection fraction, } \\
\% \text { (SD) }\end{array}$ & $62(1.2)$ & $60(0.5)$ \\
\hline \multicolumn{3}{|l|}{ Marital status, n (\%) } \\
\hline Single & $7(7.2)$ & $3(1.9)$ \\
\hline Married & $83(85.6)$ & $104(66.7)$ \\
\hline Divorced & $1(1.0)$ & $11(7.3)$ \\
\hline Widowed & $2(2.0)$ & $33(21.2)$ \\
\hline \multicolumn{3}{|l|}{ Education, n (\%) } \\
\hline Did not complete high school & $51(54.6)$ & $120(76.9)$ \\
\hline High school graduate & $3(3.1)$ & $5(3.2)$ \\
\hline College degree & $38(39.2)$ & $14(9.0)$ \\
\hline Other degree & $2(2.1)$ & $8(5.1)$ \\
\hline No degree & $0(0)$ & $5(3.2)$ \\
\hline
\end{tabular}

One hundred and forty patients $(50.7 \%$ men and $49.3 \%$ women) did not reply or replied with too many unanswered items. (figure 1) The mean age of these 140 non-responders was 58.4 years.

The final sample was predominantly married $(73.9 \%)$ and $171(67.6 \%)$ of the sample did not complete high school (table 1).

\section{Cardiac symptoms before and after coronary angiography}

The type and intensity of the symptoms that were the reason for the cardiac catheterisation were measured with a non-standardised questionnaire (multiple answers for the type of symptoms were possible). More than half of all patients $(55.3 \%)$ reported chest pain. A total of $35.4 \%$ of the patients suffered from dyspnoea and $39.4 \%$ of patients experienced palpitations.

Before coronary angiography $8.7 \%$ of the patients suffered from severe cardiac symptoms and $28 \%$ suffered from moderate discomfort. After cardiac catheterisation, although the intensity of the symptoms was regressive in many patients, in a total of $70 \%$ of patients the symptoms persisted despite angiographic exclusion of a coronary artery disease (figure 2).

\section{Comparison of mental symptoms between patients with non-cardiac chest pain and the normal population}

Data recorded after analysis of the questionnaires are reported in figure 3. With the exception of the HADS-Depression scale all questionnaires showed an increased total score in non-cardiac chest pain patients compared to the normal population. In comparison to the healthy population the non-cardiac chest pain patients showed an elevated CAQ-Total score with a relative difference of $27 \%(\mathrm{p}<0.001)$. Also, the three subscales (CAQ-F: difference of $42 \%, \mathrm{p}<0.001$; CAQ-Av: difference $28 \%$, 
Figure 2 Relative frequency of complaint intensity (\%).

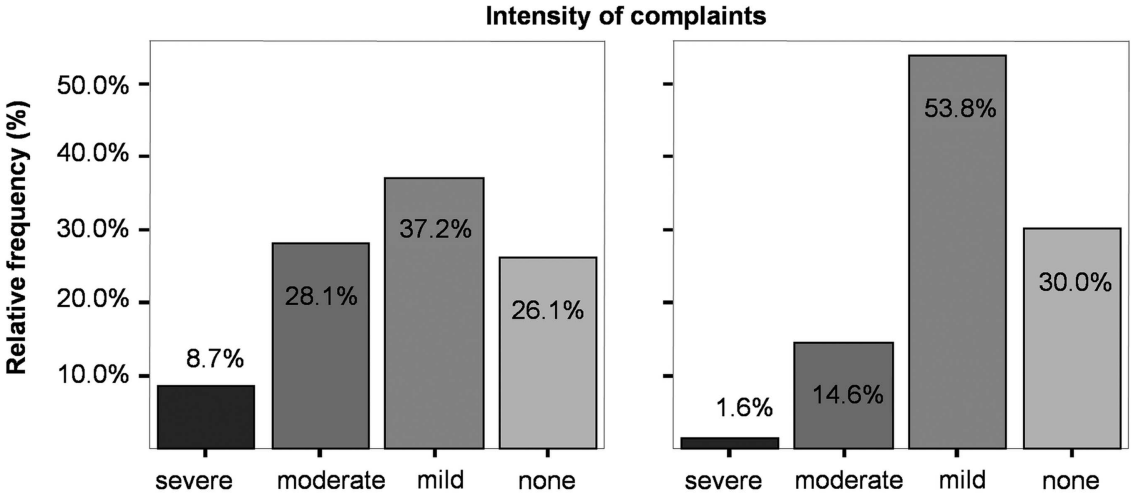

Before coronary angiography $\mathrm{p}<0.001$; CAQ-At: difference 54\%, $\mathrm{p}<0.001)$ showed significantly increased scores in patients with non-cardiac chest pain in comparison to the normal sample.

As compared with the healthy population, the noncardiac chest pain patients revealed in HADS-anxiety scale a $22 \% \quad(p=0.003)$ higher score in male and $37 \%$ $(p<0.001)$ increased score in female. In contrast, the incidence of depression, measured with the HADS-depression scale, was significantly decreased by $22.5 \%$ in the male non-cardiac chest pain patients

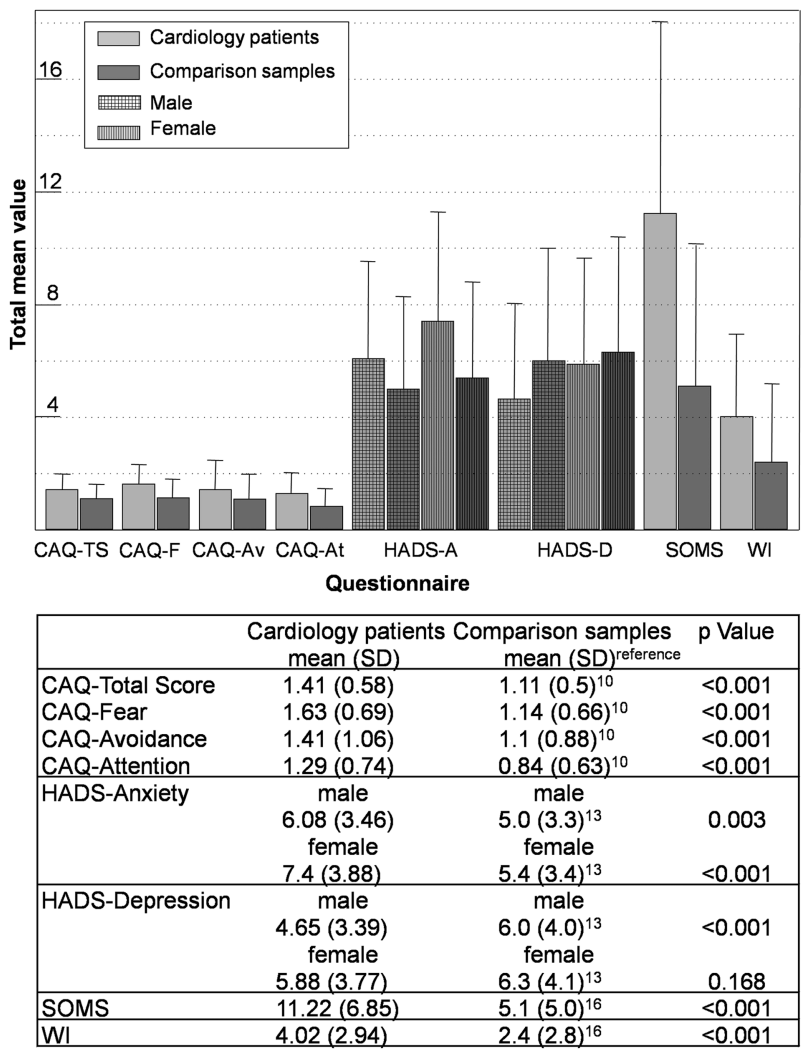

Figure 3 Comparison between non-cardiac chest pain patients and healthy population. CAQ, Cardiac Anxiety Questionnaire with the three subscales; Fear (CAQ-F), Avoidance (CAQ-Av) and Attention (CAQ At); HADS, Hospital Anxiety and Depression Scale with the two subscales; SOMS, Screening for Somatoform Disorders; WI, Whiteley Index. $(\mathrm{p}<0.001)$ in comparison to the normal sample. However, there was no significant difference between female non-cardiac chest pain patients and the normal female population in the HADS-depression scale.

The SOMS-questionnaire as measure of somatoform disorder showed a noticeable increased score with a relative difference of $120 \%(\mathrm{p}<0.001)$ in comparison to the normal sample. To compare the hypochondriacal tendencies of non-cardiac chest pain patients with the healthy population, the Whiteley Index (WI) was measured, which showed a significantly elevated score $(68 \%)$ in non-cardiac chest pain patients $(\mathrm{p}<0.001)$.

These increased incidences of psychological symptoms reflect in a lower psychological and physical quality of life in cardiac patients. Figure 4 shows the data of comparison of quality of life between cardiac patients and healthy participants, measured with the SF-12questionnaire. Male cardiology patients revealed a reduction of SF-12 total mean value of $8.8 \%$ in the physical quality of life and $5.8 \%$ in the psychological quality of life. Female cardiac patients had a decreased total mean value of physical quality of life of $13 \%$ and a decreased value of psychological quality of life of $8 \%$ in comparison to the normal population.

\section{Correlation analyses}

To measure the relationship between the persistence of cardiac symptoms and the occurrence of mental symptoms in non- cardiac chest pain patients, Spearman's correlation $(\mathrm{r}(\mathrm{s}))$ of the symptom persistence and the total mean values of the questionnaires were obtained. The detailed results are illustrated in table 2 .

The correlation analyses showed a low positive correlation (Spearman's r: r(s)) between the symptom persistence and total mean values of the following questionnaires: CAQ-Total score, CAQ-Fear, CAQAttention, HADS-Anxiety, HADS-Depression, SOMS and Whiteley Index. Between the persistence of symptoms and the mean value of CAQ-Avoidance exists a moderate positive correlation.

Accordingly, the negative Spearman correlation showed that persistence of symptoms was associated with a reduced quality of life. 
Figure 4 Comparison of quality of life (QoL) between non-cardiac chest pain patients and healthy population. Physical QoL: Physical quality of life subscale of

Psychological quality of life subscale of the SF-12; t-test: ${ }^{*} p<0.01 ; \# p=0.013 ;+p<0.001$; $\$ p<0.001$ the SF-12; Psychol QoL:

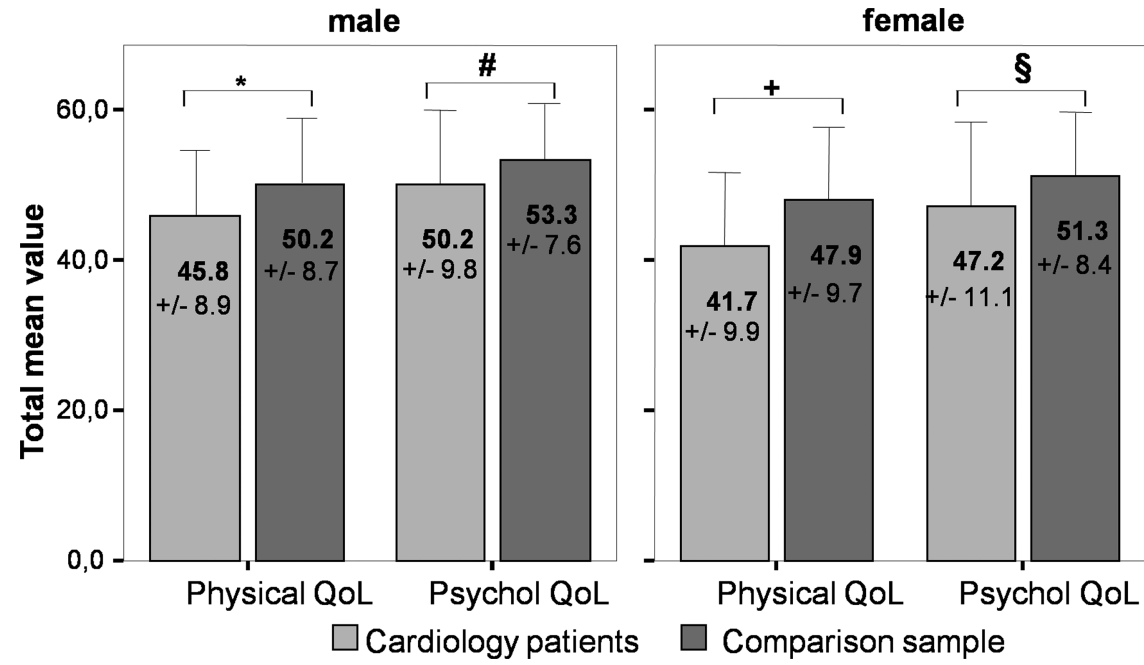

Additionally, Spearman correlation analyses for the total mean values of the questionnaires and the quality of life revealed a negative relationship between all mental symptoms and the physical and psychological quality of life (table 2).

\section{DISCUSSION}

About $20 \%$ of patients with chest pain have normal coronary angiograms. ${ }^{28}$ Psychopathological disorders are important differential diagnoses in these chest pain patients. ${ }^{29}$ As this diagnosis is often not recognised, the healthcare system is heavily burdened. ${ }^{30}$ Therefore, patients with non-cardiac chest pain should be examined early on for psychopathological disorders. ${ }^{11} 31$

In this study, the majority of patients $(70 \%)$ with noncardiac chest pain or other cardiac symptoms were still suffering from their symptoms 6-18 months after the inconspicuous coronary angiography. This finding is consistent with the data of previous studies. ${ }^{31}{ }^{32}$ Thus, it

\begin{tabular}{|c|c|c|c|c|}
\hline & Questionnaire & $\mathbf{N}$ & Spearman's r(s) & p Value \\
\hline \multirow[t]{10}{*}{ Persistence of cardiac symptoms } & CAQ-Total & 221 & 0.22 & 0.01 \\
\hline & CAQ-Fear & 231 & 0.24 & $<0.001$ \\
\hline & CAQ-Avoidance & 241 & 0.64 & 0.326 \\
\hline & CAQ-Attention & 233 & 0.24 & $<0.001$ \\
\hline & HADS-Anxiety & 241 & 0.28 & $<0.001$ \\
\hline & HADS-Depression & 242 & 0.24 & $<0.001$ \\
\hline & SOMS & 244 & 0.38 & $<0.001$ \\
\hline & Whiteley Index & 194 & 0.33 & $<0.001$ \\
\hline & SF-12-physical & 160 & -0.3 & $<0.001$ \\
\hline & SF-12-psychological & 160 & -0.173 & 0.3 \\
\hline \multirow[t]{2}{*}{ CAQ-Total } & SF-12-physical & 156 & -0.48 & $<0.001$ \\
\hline & SF-12-psychological & 156 & -0.38 & $<0.001$ \\
\hline \multirow[t]{2}{*}{ CAQ-Fear } & SF-12-physical & 159 & -0.29 & $<0.001$ \\
\hline & SF-12-psychological & 159 & -0.44 & $<0.001$ \\
\hline \multirow[t]{2}{*}{ CAQ-Avoidance } & SF-12-physical & 165 & -0.53 & $<0.001$ \\
\hline & SF-12-psychological & 165 & -0.14 & $<0.001$ \\
\hline \multirow[t]{2}{*}{ CAQ-Attention } & SF-12-physical & 163 & -0.26 & 0.01 \\
\hline & SF-12-psychological & 163 & -0.18 & 0.01 \\
\hline \multirow[t]{2}{*}{ HADS-Anxiety } & SF-12-physical & 163 & -0.41 & $<0.001$ \\
\hline & SF-12-psychological & 163 & -0.63 & $<0.001$ \\
\hline \multirow[t]{2}{*}{ HADS-Depression } & SF-12-physical & 163 & -0.48 & $<0.001$ \\
\hline & SF-12-psychological & 163 & -0.63 & $<0.001$ \\
\hline \multirow{2}{*}{ SOMS } & SF-12-physical & 165 & -0.44 & $<0.001$ \\
\hline & SF-12-psychological & 165 & -0.41 & $<0.001$ \\
\hline \multirow[t]{2}{*}{ Whiteley Index } & SF-12-physical & 132 & -0.47 & $<0.001$ \\
\hline & SF-12-psychological & 132 & -0.41 & $<0.001$ \\
\hline
\end{tabular}


could be shown in a study of 176 patients that $81 \%$ of patients with non-cardiac chest pain suffered from persistent cardiac symptoms over a period of 12 years. ${ }^{32}$

It is obvious that these patients obtained additional somatic diagnostics and therapies for the treatment of the non-cardiac chest pain, including cardiac catheterisation. According to a study by Potts and Bass, ${ }^{33} 71 \%$ of patients in the course received heart-specific medication despite inconspicuous results in coronary angiography.

In this study, the incidences of general-anxiety (HADS), heart-focused anxiety (CAQ), hypochondria (Whiteley Index), depression (HADS-D) and somatoform disorder (SOMS) were measured in patients with non-cardiac chest pain with the help of well-validated questionnaires. It could be demonstrated on the basis of increased total scores of the questionnaires that patients with non-cardiac chest pain more often suffer from psychopathological symptoms (except depression) in comparison to the healthy general population. Why the non-cardiac chest pain patients did not show increased values of the HADS-D questionnaire remains unclear. Previous studies also showed this low incidence of depression in non-cardiac chest pain patients. It could be shown that chest pain indirectly increases the incidence of depression. Nevertheless in combination with a concomitant panic disorder caused by chest pain the incidence of depression is much higher. ${ }^{9}$

In addition, it was shown that the affected patients have a significantly lower psychological and physical quality of life compared to the normal population.

Recent data confirm these results, showing that patients with non-cardiac chest pain have the same reduced quality of life as patients with cardiac-related chest pain. ${ }^{34}$

The interaction analysis of this study revealed a positive correlation between the persistence of the symptoms and the increased total scores of the questionnaires. These results support the opinion that patients with non-cardiac chest pain should receive a psychological or psychiatric examination in order to initiate appropriate psychosomatic therapy early if necessary. So it is probably possible to prevent redundant somatic diagnostics and treatment and to improve the quality of life of these patients significantly. ${ }^{35}$ As a psychosomatic screening tool the use of the standardised and validated questionnaires was very practicable, even for cardiologists without psychosomatic training and without remarkable expenditure of time. The entire psychosomatic screening consists of 98 questions. The complete filling out of all items requires about $120 \mathrm{~min}$ per patient. This time frame is acceptable for inpatients as well as for outpatients. The analysis of these questionnaires takes about $15 \mathrm{~min}$ and can also be performed by nurses. Taken together, the time required for this diagnosis is justified.

Some questions cannot be answered adequately by this study. So it cannot be distinguished whether the psychopathological symptoms cause the cardiac symptoms or if the cardiac symptoms provoke the psychopathological disorders. Another unresolved fact of this study is whether or not a psychosomatic therapy can improve the outcome and the quality of life in these patients. However, some recent works showed that the prognosis of patients with heart-focused anxiety can be improved with the help of cognitive-behavioural therapies. ${ }^{36} 37$ Whether these therapies additionally decrease the overuse of the healthcare system remains unclear.

Some limitations of this study must be noted. The interpretability of the results is reduced because the health status of the participants was only measured using subjective ratings. A full psychiatric examination of the patients using a standardised interview such as SCID-I/II (Structured Clinical Interview for DSM-IV) was not performed. ${ }^{38}$ Although an attempt was made to match age and gender of the cardiac patients with the control patients, it is possible that the control population is slightly different compared to the cardiac patients. Although a participation rate of $64 \%$ is very high, the remaining $36 \%$ of patients who did not reply to the study invitation could cause a selection error. In particular, people with severe mental health problems could have chosen to participate in this survey. This would result in overestimation of mental symptoms in patients with inconspicuous coronary angiography. A further limitation of this study was the lack of detailed information about other possible non-cardiac causes of chest pain like gastric disorders, oesophageal spasm or skeletal causes. Additionally, no investigations were performed to exclude small vessel disease. Hence, other somatic causes of chest pain than coronary heart disease were not totally ruled out. Another limitation of the study is that the questionnaires values of the comparison samples were taken from previous published data. Therefore, relevant errors caused by insufficient matching of the comparison groups may occur. Further, it cannot be ruled out that the comparison groups contain some patients with an inconspicuous coronary angiography or cardiac symptoms. In the current study design all patients were invited at the same time point. This design has certain advantages and disadvantages. Owing to the relatively long time interval between the angiography and the invitation to the study, some new somatic disorders may have occurred additionally, which could influence the results. On the other hand, the simultaneous survey of all patients ruled out seasonal, political or economic bias.

\section{CONCLUSION}

Patients with angiographic exclusion of a coronary artery disease have a significantly increased incidence of mental symptoms compared to the healthy population. Therefore, a psychosomatic diagnostic should be performed early in these patients. On the basis of this work we recommend the use of the HADS-questionnaire, CAQ-questionnaire, WI-questionnaire and the SOMSquestionnaires as initial screening tools for mental symptoms. These standardised questionnaires are very 
practicable even for internal wards. These diagnostic tools may prevent repeated utilisation of the healthcare system and this could help to reduce costs for these patients due to initiation of an early psychosomatic therapy.

Competing interests None.

Patient consent No.

Ethics approval The current registry was performed in compliance with the guidelines for good clinical practice and the Declaration of Helsinki and was performed according the guidelines of the institutional ethical review board.

Provenance and peer review Not commissioned; externally peer reviewed.

Open Access This is an Open Access article distributed in accordance with the Creative Commons Attribution Non Commercial (CC BY-NC 3.0) license, which permits others to distribute, remix, adapt, build upon this work noncommercially, and license their derivative works on different terms, provided the original work is properly cited and the use is non-commercial. See: http:// creativecommons.org/licenses/by-nc/3.0/

\section{REFERENCES}

1. Rosch PJ. Risk of coronary artery disease. JAMA 1983;249:2178-9.

2. Joukamaa $M$, Heliovaara $M$, Knekt $P$, et al. Mental disorders and cause-specific mortality. Br J Psychiatry 2001;179:498-502.

3. Mykletun A, Bjerkeset O, Overland S, et al. Levels of anxiety and depression as predictors of mortality: the HUNT study. $\mathrm{Br} \mathrm{J}$ Psychiatry 2009;195:118-25.

4. White KS, Craft JM, Gervino EV. Anxiety and hypervigilance to cardiopulmonary sensations in non-cardiac chest pain patients with and without psychiatric disorders. Behav Res Ther 2010;48:394-401.

5. Hotopf M, Mayou R, Wadsworth M, et al. Psychosocial and developmental antecedents of chest pain in young adults. Psychosom Med 1999;61:861-7.

6. Carmin CN, Wiegartz PS, Hoff JA, et al. Cardiac anxiety in patients self-referred for electron beam tomography. J Behav Med 2003;26:67-80.

7. Eckart WU. Wenn die Seele das Herz quält. Dtsch Med Wochenschr 2003:2155-8.

8. Kisely S, Guthrie E, Creed F, et al. Predictors of mortality and morbidity following admission with chest pain. J R Coll Physicians Lond 1997;31:177-83.

9. Carter CS, Servan-Schreiber D, Perlstein WM. Anxiety disorders and the syndrome of chest pain with normal coronary arteries: prevalence and pathophysiology. J Clin Psychiatry 1997;58(Suppl 3): 70-3; discussion 74-75.

10. Kisely SR. The relationship between admission to hospital with chest pain and psychiatric disorder. Aust $N Z J$ Psychiatry 1998;32:172-9.

11. White KS, Raffa SD, Jakle KR, et al. Morbidity of DSM-IV Axis I disorders in patients with noncardiac chest pain: psychiatric morbidity linked with increased pain and health care utilization. $J$ Consult Clin Psychol 2008;76:422-30.

12. Eifert GH, Thompson RN, Zvolensky MJ, et al. The cardiac anxiety questionnaire: development and preliminary validity. Behav Res Ther 2000;38:1039-53

13. Reiss S, Peterson RA, Gursky DM, et al. Anxiety sensitivity, anxiety frequency and the prediction of fearfulness. Behav Res Ther 1986;24:1-8.
14. Eifert GH, Zvolensky MJ, Lejuez CW. Heart-focused anxiety and chest pain: a conzeptual and clinical review. Clin Psychol Sci Pract 2000;7:403-17.

15. Hoyer J, Eifert GH, Einsle F, et al. Heart-focused anxiety before and after cardiac surgery. J Psychosom Res 2008;64:291-7.

16. Zigmond AS, Snaith RP. The hospital anxiety and depression scale. Acta Psychiatr Scand 1983;67:361-70.

17. Herrmann C. International experiences with the Hospital Anxiety and Depression Scale-a review of validation data and clinical results. $J$ Psychosom Res 1997;42:17-41.

18. Hinz A, Schwarz R. [Anxiety and depression in the general population: normal values in the Hospital Anxiety and Depression Scale]. Psychother Psychosom Med Psychol 2001;51:193-200.

19. Rief W, Hiller W, Heuser J. SOMS-Screening für Somatoforme Störungen (Manual zum Fragebogen). 1997.

20. Escobar JI, Waitzkin H, Silver RC, et al. Abridged somatization a study in primary care. Psychosom Med 1998;60:466-72.

21. Rief W, Hessel A, Braehler E. Somatization symptoms and hypochondriacal features in the general population. Psychosom Med 2001;63:595-602.

22. Rief W, Hiller W, Geissner E, et al. Hypochondrie: Erfassung und erste klinische Ergebnisse. Zeitschrift für Klinische Psychologie 1994;23:34-42.

23. Hiller W, Rief W, Fichter MM. Dimensional and categorical approaches to hypochondriasis. Psychol Med 2002;32:707-18.

24. Hiller W, Rief W. Internationale Skalen für Hypochondrie. Deutschsprachige Adaptation des Whiteley-Index (WI) und der Illnes Attitude Scales (IAS). Huber 2004

25. Ware J Jr, Kosinski M, Keller SD. A 12-Item Short-Form Health Survey: construction of scales and preliminary tests of reliability and validity. Med Care 1996;34:220-33.

26. Gandek B, Ware JE, Aaronson NK, et al. Cross-validation of item selection and scoring for the SF-12 Health Survey in nine countries: results from the IQOLA Project. International Quality of Life Assessment. J Clin Epidemiol 1998;51:1171-8.

27. Bullinger M, Kirchberger I. SF-36. Fragebogen zum Gesundheitszustand. Handanweisung. 1998.

28. Vermeltfoort IA, Raijmakers PG, Riphagen II, et al. Definitions and incidence of cardiac syndrome $X$ : review and analysis of clinical data. Clin Res Cardiol 2010;99:475-81.

29. Ho KY, Kang JY, Yeo B, et al. Non-cardiac, non-oesophageal chest pain: the relevance of psychological factors. Gut 1998;43:105-10.

30. Albertsson P, Emanuelsson $\mathrm{H}$, Karlsson T, et al. Morbidity and use of medical resources in patients with chest pain and normal or near-normal coronary arteries. Am J Cardiol 1997;79:299-304.

31. Sheps DS, Creed F, Clouse RE. Chest pain in patients with cardiac and noncardiac disease. Psychosom Med 2004;66:861-7.

32. Lichtlen $P R$, Bargheer $K$, Wenzlaff $P$. Long-term prognosis of patients with angina-like chest pain and normal coronary angiographic findings. J Am Coll Cardiol 1995;25:1013-18

33. Potts SG, Bass CM. Psychological morbidity in patients with chest pain and normal or near-normal coronary arteries: a long-term follow-up study. Psychol Med 1995;25:339-47.

34. Cheung TK, Hou X, Lam KF, et al. Quality of life and psychologica impact in patients with noncardiac chest pain. J Clin Gastroenterol 2009;43:13-18.

35. Mayou RA, Bass CM, Bryant BM. Management of non-cardiac chest pain: from research to clinical practice. Heart 1999;81:387-92.

36. Esler JL, Barlow DH, Woolard RH, et al. A brief cognitive-behavioral intervention for patients with noncardiac chest pain. Behavior Therapy 2003;34:129.

37. Mayou RA, Bryant BM, Sanders D, et al. A controlled trial of cognitive behavioural therapy for non-cardiac chest pain. Psychol Med 1997;27:1021-31.

38. Grandi S, Fabbri S, Tossani E, et al. Psychological evaluation after cardiac transplantation: the integration of different criteria. Psychother Psychosom 2001;70:176-83. 